\title{
The Effects of Planned Focus on Form on Iranian EFL Learners' Oral Accuracy
}

\author{
Farahman Farrokhi \\ Department of English Language \& Literature \\ University of Tabriz, Tabriz, Iran \\ E-mail: ffarrokhi20@yahoo.co.uk \\ Mohammad Hassan Chehrazad (Corresponding author) \\ Department of English Language \& Literature \\ University of Tabriz, Tabriz, Iran \\ Tel:98-914-405-4315_E-mail:chehrazad88@ms.tabrizu.ac.ir \& mhchehrazad@yahoo.com

$\begin{array}{ll}\text { Received: August 26, } 2011 & \text { Accepted: September 14, 2011 Published: February 1, } 2012 \\ \text { doi:10.5430/wje.v2n1p70 } & \text { URL: http://dx.doi.org/10.5430/wje.v2n1p70 }\end{array}$

\begin{abstract}
One of the limitations of the meaning focused instruction in an EFL situation such as Iran is that a communicative approach helps Iranian learners to become fluent, but is insufficient to ensure comparable levels of oral accuracy. The purpose of this study was to investigate whether planned focus on form, and also what type of corrective feedback, would be useful for Iranian EFL learners' oral accuracy. To this end, the study employed a quasi experimental design. Three intact classes were randomly selected as the control group $(n=17)$, recast group $(n=19)$ as experimental group 1 , and delayed explicit and metalinguistic group $(n=21)$ as the experimental group 2 respectively. All groups participated in six sessions of the task of story retelling. For all groups, learners were asked to read and summarize their own assigned story in a time limit of four minutes and retell it to the class. For the recast group, students were provided with recasts on their simple past tense errors; for the delayed explicit and metalinguistic group, the researcher corrected the learners' errors after they finished the retelling; and for the control group, there were no feedback on learners' errors. Learners' improvement was measured by their oral accuracy during the six sessions of story retelling. One-way ANOVAs with post hoc comparisons indicated that all CF groups significantly outperformed the control group in the session six of story retelling and that the two feedback types were equally effective in promoting learners' oral accuracy. These findings suggest that the planned focus on form can be an effective tool for the development of oral accuracy in the EFL situations. It can also be concluded that intensive recasts which are repeatedly focused on a particular structure are not different from explicit types of feedback in terms of their effectiveness.
\end{abstract}

Keywords: Focus on form, Planned focus on form, Explicit focus on form, Recast, Metalinguistic feedback, Accuracy

\section{Introduction}

The non-interventionist focus on meaning's problem, which helped learners to become fluent, but was insufficient to ensure comparable levels of accuracy, led to the introduction of a viable third option by Long (1991) called focus on form, which attempts to capture the strengths of an analytic approach while dealing with its limitations. The current focus on form movement (for example, Doughty \& Williams, 1998) is an attempt to inject well considered explicit instruction back into language lessons without abandoning the positive features and results of the communicative approach. Doughty (2001) noted "the factor that distinguishes focus on form from other pedagogical approaches is the requirement that focus on form involves learners briefly and simultaneously attending to form, meaning and use during one cognitive event" (p. 211).

\section{Literature Review}

\subsection{Historical background for focus on form}

The popular position in language teaching has been that the teachers or syllabus designers' first task is to analyze the target language, eventually, it is the learner's job to synthesize the parts for use in communication, which is why Wilkins (1976) called this the synthetic approach to syllabus design. Depending on the analyst's linguistic preferences, the L2 is broken down into words and grammar rules, and etc. and presented to the learners in a linear and additive fashion 
according to such criteria as frequency, or difficulty. According to Long and Robinson (1998), "Synthetic syllabi, together with the corresponding materials, methodology, and classroom pedagogy, lead to lessons with a focus on forms. Moreover, as it is mentioned in Long and Robinson (1998), "synthetic syllabi, methods, and classroom practices either ignore language learning processes or tacitly assume a discredited behaviorist model in a way that the learner's role is to synthesize the pieces for use in communication" (p. 17). In addition to these problems, there is no needs analysis to identify a particular learner's or group of learners' communicative needs.

Recognition that the traditional synthetic syllabi and teaching procedures were not working as they were supposed to, led teachers, syllabus designers, and SLA theorists, to advocate the abandonment of a focus on forms in the classroom in favor of an equally single-minded focus on meaning. To this end, CLT was initiated in an effort to shift away from a sole focus on forms evident in the earlier structural approaches towards a focus on meaning and language use. Inspired by a theory of communicative competence (Hymes, 1971), its primary concern was to develop learners' ability to use the second language meaningfully and appropriately in real life communication. CLT is not a uniform approach, however. One can distinguish between a strong and a weak form of CLT (Howatt, 1984). According to Wilkins (1976), therefore, a weak form of CLT is synthetic in its approach, as it advocates the teaching of linguistic units in isolation without allowing learners to infer rules during the holistic use of language. Conversely, a strong form of CLT argues that "language is acquired through communication" (Howatt, 1984, p. 279). The strong version, thus, reflects what Wilkins refers to as an analytic approach to teaching, i.e. an approach in which it is the learner's task to analyze and discover the language. For language educators (Ellis, 2003), Task-based language teaching represents a strong form of CLT. It views "tasks as a means of enabling learners to learn a language by experiencing how it is used in communication" (Ellis, 2003, p. 28)

Although a purely analytic, a meaning-based form of task based teaching was a step forward from synthetic approaches, SLA research suggests that, if native-like proficiency is the goal of instruction, such an approach will not suffice either. There is an ever-growing consensus among L2 researchers that, in order to be effective, task based syllabuses, and analytical approaches in general, need to be augmented, at least at times by some type of grammar instruction ( Long \& Robinson, 1998; Long, 2000; Ellis, 2003).This was based on studies showing that learners, if left completely to their own devices, are unlikely to attain native-like grammatical competence, despite even extensive contact with the target language(e.g., Long, 1996; Long \& Robinson, 1998). For example, evaluations of French immersion programs in Canada have found that learners typically become fluent and comprehend L2 at native levels as a result of content-based instruction, and, yet, "their productive skills remain far from native like, particularly with respect to grammatical competence" (Swain, 1991). Recognition of these kinds of problems with analytic approaches as well as problems of synthetic approaches led to the introduction of a viable third option by Long (1991) called focus on form, which attempts to capture the strengths of an analytic approach while dealing with its limitations. Long and Robinson (1998) defines focus on form instruction as:

During a meaning-focused classroom lesson, focus on form often consists of an occasional shift of attention to linguistic code features by the teacher and/or one or more of the students, triggered by perceived problem with comprehension or production. (p. 23)

\subsection{Theoretical rational for focus on form}

\subsubsection{Long's Interaction Hypothesis (IH)}

The Interaction Hypothesis, then, suggests a number of ways in which interaction can contribute to language acquisition. In general terms, it posits that the more opportunities for negotiation there are, the more acquisition is. More specifically, it suggests (1) that when interactional modifications lead to comprehensible input via the decomposition and segmenting of input, acquisition is facilitated; (2) that when learners receive feedback, acquisition is facilitated; (3) that when learners are pushed to reformulate their own utterances, acquisition is promoted. In his initial formulation of the $\mathrm{IH}$, Long (1983) emphasized the role played by interaction in making input comprehensible. In the later version, Long (1996) acknowledged that interaction can facilitate acquisition by assisting learners' production. The general claim of both early and late versions of the $\mathrm{IH}$ is that engaging in interpersonal oral interaction in which communication problems arise and are negotiated facilitates incidental language acquisition. The updated version of the IH also offered a much richer view of how negotiation can assist language learning. As in early version, "negotiation was seen as providing learners with positive evidence" (Long, 1996, p. 413).The later version of the IH also posits two other ways in which interaction can contribute to acquisition: through the provision of negative evidence and through opportunities for modified output. He (ibid) defined negative evidence as "input that provides direct or indirect evidence of what is ungrammatical. It arises when learners receive feedback on their attempts to use the L2" (p.413). 


\subsubsection{Output Hypothesis}

Swain $(1985,1995)$ advanced the Comprehensible Output Hypothesis as a complement to Krashen's Input Hypothesis (1982). Swain (1985) proposed that production (especially pushed output) may encourage learners to move from semantic (top-down) to syntactic (bottom-up) processing. Production requires learners to process syntactically; they have to pay some attention to form. Researchers have noted, however, that these functions are not necessarily performed in the generation of learner output; output needs to be supplemented by consistent corrective feedback in order to trigger these processes (e.g., Swain \& Lapkin, 1998). As Swain (1991) herself acknowledges, "If students are given insufficient feedback or no feedback regarding the extent to which their messages have successfully been conveyed output may not serve these roles" (p. 98).

\subsubsection{Schmidt's Noticing Hypothesis}

According to Long (2000), focus on form is largely motivated by, albeit not exclusively, by Schmidt's Noticing Hypothesis (Schmidt, 1990, 2001). This hypothesis holds that noticing, a cognitive process that involves attending to the input learners receive, is inevitably a conscious process and is a necessary condition for second language learning. Schmidt $(1990,2001)$ has argued that attention and its subjective correlates noticing, i.e. registering formal features in the input, and noticing the gap, i.e. identifying how the input to which the learner is exposed differs from the output the learner is able to generate, are essential processes in L2 acquisition. Attention is generally considered a necessary condition for converting input into intake in the field of SLA (Schmidt, 1990, 2001); Sharwood Smith, 1993). Gass (1990), for example, explains that "nothing in the target language is available for intake into a learner's existing system unless it is consciously noticed" (p.136).

\subsection{Implicit vs. explicit knowledge}

Implicit knowledge is intuitive, procedural, systematically variable, automatic, and thus available for use in fluent, unplanned language use. Explicit knowledge is conscious, declarative, anomalous, and inconsistent and generally only accessible through controlled processing in planned language use. Explicit knowledge may contribute to language development by facilitating the development of implicit knowledge (Ellis, 2005). This involves the consideration of what has become known interface hypothesis, which focuses on whether explicit knowledge plays any role in L2 acquisition (Ellis, 2005). Based on categorization of Ellis, three positions can be recognized:

\subsubsection{Zero Option}

As a result of early work in L2 acquisition which provided evidence of natural route of development, a number of researchers (for example, Dulay \& Burt, 1973; Krashen, 1982) and also educationalists (Terrol, 1977; Prabhu, 1987) proposed that classroom language learning will proceed more effectively if language learners are allowed to construct their interlanguages naturally in the same way as they would if they were learning grammar through the process of learning how to communicate. The zero option entails not only a rejection of planned intervention by means of presentation and practice of different items and rules but also of unplanned intervention in the form of error correction. Krashen (1982, p. 74) referred to error correction as a serious mistake.

\subsubsection{Interface Hypothesis}

According to the interface hypothesis, instruction facilitates acquisition by (1) supplying learners with conscious rules, and (2) providing practice to help them to convert this conscious, controlled knowledge into automatic knowledge. Sharwood Smith (1981) developed a full interface model. Dekeyser (1998) made a similar claim, drawing on skill building theory; declarative knowledge is converted into procedural knowledge by means of practice that involves the learner in communicative behavior.

\subsubsection{Weak Interface Hypothesis}

This hypothesis claims that formal instruction acts as an aid to acquisition, not by actually bringing about the internalization of new linguistic features, but rather by providing the learner with 'hooks, points of access'. As Gass puts it, instruction "triggers the initial stages in what eventually results in grammar restructuring" (1997, p. 137).

\subsection{Planned vs. incidental focus on form}

Ellis (2001) categorized focus on form into planned and incidental focus on form. In planned focus on form, pre-selected linguistic items are targeted during a meaning-focused activity. Planned focus on form can be realized either through input flood (Trahey \& White, 1993) and input enhancement (Sharwood Smith, 1993) or output in the form of corrective feedback on errors in the use of pre-targeted forms (Ellis, 2001). Incidental focus on form (Ellis, 2001) occurs spontaneously, without prior intention, during meaning-focused activities and targets a variety of linguistic items. While planned focus on form is intensive, focusing frequently on the same linguistic structure, incidental focus on form has a 
more extensive focus, with many linguistic structures being targeted but on only one or two occasions (Ellis et al., 2001a).

\subsection{Reactive focus on form}

Another distinction that has been made is between reactive and preemptive focus on form (Ellis et al., 2001a, 2001b; Long \& Robinson, 1998). While Long claims that focus on form is purely reactive, Ellis (2001) claims that it comes in two forms; preemptive focus on form and reactive focus on form. Reactive focus on form has also been known as error correction, corrective feedback, or negative evidence/feedback (Long, 1996), and occurs when, in the context of meaning-focused activities, learners' attention is drawn to errors in their production.

\subsubsection{Implicit vs. explicit feedback}

Doughty and Williams (1998) assert that focus on form interpretations vary from a very narrow and implicit view introduced by Long (1991) to a general, liberal, and more explicit view suggested in the findings of Dekeyser (1998); Swain (1998). Since explicit feedback depends on metalinguistic information to sustain error correction, students must comprehend the language used in the metalinguistic explanation. Thus, students who do not have the specialized vocabulary and grammar awareness may not be able to make use of this feedback (Carroll \& Swain, 1993). On the other hand, implicit feedback indirectly and incidentally makes learners aware of their non-target-like use of certain linguistic features.

\subsubsection{Metalinguistic feedback}

This consists of utterances that provide comments, information, or questions related to the well-formedness of the learner's utterance. (Lyster, 2004, p. 405).

L: My mother is in Spain two years ago.

T: Well, remember we talked about past tense. You should say "My mother was".

\subsubsection{Recast}

\subsubsection{Definition}

An utterance that "rephrases the learner's utterance by changing one or more components (subject, verb, object) while still referring to its central meaning" (Long, 1996, p. 436).

\subsubsection{Recast: Implicit or explicit?}

The prevailing view in the recast literature is that recasts constitute an implicit form of negative feedback. According to Ellis (2008) "arguably recasts should not be viewed as necessarily implicit but rather depending on the linguistic signals that encode them and the discoursal context, as more or less implicit/explicit" (p. 230). Corrective recasts are clearly explicit, as is evident in this example from Doughty and Varela (1998):

L: I think that the worn will go under the soil.

T: I think that the worn will go under the soil?

L: (no response)

T: I thought that the worn would go under the soil

L: I thought that the worn would go under the soil

\subsubsection{Recast: Positive or negative evidence?}

According to Ellis and Sheen (2006), recasts can serve as both positive and negative evidence if learner perceive the teacher's corrective intention but only as positive evidence if learners are not consciously aware of their illocutionary force (see also Leeman, 2003). Although there is evidence that recasts affording just positive evidence can facilitate acquisition, it remains possible (but not yet demonstrated) that recasts that supply both positive and negative evidence are even more effective.

\subsubsection{Intensive vs. extensive recasts}

Intensive recasts are directed at a single structure (as in Doughty \& Varela's, 1998), and encouraged the treatment of recasts as an explicit feedback. On the other hand, extensive recasts are directed at different structures, and encouraged the treatment of recasts as an implicit feedback.

\subsection{Accuracy}

It concerns "the extent to which the language produced conforms to target language norms" (Skehan, 1996, p. 22). 


\section{Methodology}

\subsection{Aims of the study}

The purpose of the current study was on the investigation of the different effects of existence or non-existence of planned focus on form, corrective feedback focused on the simple past tense errors, on the Iranian EFL learners' oral accuracy. In addition, the purpose was to investigate different effects of different corrective feedback types, provided during six sessions of story retelling and treatment, on the Iranian EFL learners' oral accuracy. In other words, it aimed to investigate both the effects of existence or non-existence of corrective feedback and the different effects of different feedback types, in this study, recasts provided intensively on the learners' simple past tense errors during the story retelling task and delayed explicit and metalinguistic feedback provided to the learners at the end of their story retelling task, on the Iranian EFL learners' oral accuracy.

\subsection{Research Questions and Hypotheses}

To achieve the purpose of the study, the following research questions and hypotheses were formulated:

Research Question 1(RQ1): Do learners who have received planned focus on form, corrective feedback, on their simple past tense errors in their story retellings show greater improvement on their oral accuracy than those who have not?

1) Do learners who have received recasts on their simple past tense errors show greater improvement on their oral accuracy than learners who have not?

2) Do learners who have received delayed explicit and metalinguistic feedback on their simple past tense errors show greater improvement on their oral accuracy than learners who have not?

Null Hypothesis 1 (H01): There is no significant difference between oral accuracy of learners who have received feedback and those who have not received feedback.

1) There is no significant difference between oral accuracy of learners who have received recasts and those who have not received feedback.

2) There is no significant difference between oral accuracy of learners who have received delayed explicit and metalinguistic feedback and those who have not received feedback.

Alternative Hypothesis 1 (H1): There is a significant difference between oral accuracy of learners who have received feedback and those who have not received feedback.

1) Learners who have received recasts outperform those learners who have received no feedback.

2) Learners who have received delayed explicit and metalinguistic feedback outperform those learners who have received no feedback.

Research Question 2 (RQ2): Do learners who have received delayed explicit and metalinguiatic feedback on their simple past tense errors show greater improvement on their oral accuracy than those who have received recasts?

Null Hypothesis 2 (H02): There is no significant difference between the oral accuracy of learners who have received recasts and those who have received delayed explicit and metalinguistic feedback.

Alternative Hypothesis 2 (H2): Learners who receive delayed explicit and metalinguistic feedback outperform those who receive recasts.

\subsection{Participants}

This study was conducted in Pardis, an English school in Tabriz, Iran. Three intact classes were selected. The number of learners who participated in the study was 57. They are called low- intermediate based on their scores on the placement test or on the previous term's achievement test. Most of them were from Tabriz and were speakers of Azeri. They were all between 15 and 22 years old, and all of them were male. The teaching approach adopted by this school placed emphasis on developing communicative skills in English. They received between 4.5 hours of English language instruction every week. The only opportunity for them was this formal classroom interaction. They had no or little opportunity for informal interaction outside the classroom. They had to speak English in the classroom, and they were not allowed to use Azeri or Persian in the classroom. The general English test, KET (Key English Test), was used to establish participants' homogeneity and those who got between 40-55 participated in the study. There were two experimental groups, and one control group. The chosen intact classes were randomly assigned to the following groups:

Group 1, Control group $(\mathrm{n}=17)$ : They received no feedback on their erroneous utterances.

Group 2, Experimental group $1(\mathrm{n}=19)$ : They received recasts on their simple past tense errors during their oral retelling. 
Group 3, Experimental group 2 (21): They received delayed explicit and metalinguistic feedback on their simple past tense errors after they finished their story retelling.

\subsection{Design of the study}

The study employed a quasi experimental design. All groups' members participated in six sessions of the task of story retelling. The control group and the two experimental groups' members differed according to the opportunity to receive feedback in the story retelling task. In other words, unlike the two experimental groups which received feedback on their simple past tense errors, the control group' members received no feedback. The two experimental groups differed in terms of the type of feedback they received; indeed, the experimental group 1, group 2 in the study, received recasts and the experimental group 2, group 3 in the study, received delayed explicit and metalinguistic feedback on their simple past tense errors during the treatment sessions. The independent variable of the study was "planned focus on form" which was operationlized as the recasts and delayed explicit and metalinguistic feedback to draw learners' attention to erroneous linguistic form, simple past tense, during and after the story retelling task. Oral accuracy was considered as the dependent variable of the study.

\subsection{Target structure}

The focus of this study was the simple past tense. It was chosen for two reasons. First, learners at the lower intermediate level are likely to already be familiar with this structure. The purpose was not to examine whether corrective feedback assists the learning of completely new structure, but whether it enables learners to gain greater control over a structure they have already partially mastered. The second reason was that past tense is known to be problematic for learners and to cause errors. (Doughty \& Varela, 1998); thus, it was hypothesized that although learners at this level would have a partial explicit knowledge of this structure, they would make errors in its use, especially in oral production. Pretesting demonstrated that this was indeed the case: On the story retelling of first session, which served as an oral pre test, the learners scored a mean of $60.96 \%$ on past tense.

\subsection{Procedures}

Before describing the instructional and testing procedures, it is essential to mention that the researcher was the instructor of all groups and conducted the research individually. After the participants and the materials were chosen, the procedure commended. Although all participants were at the low intermediate level based on the placement test of the school and their scores on the achievement tests of the previous terms, two sessions before starting the treatment sessions, the general English test, KET (Key English Test), was used and those who scored between 40-55 were selected as the participants of the study. This way of selection of participants made us certain about their homogeneity. The instructional treatments were provided during six training sessions, each of which lasted approximately 45 minutes. Every session of the instruction started with normal instruction of the institute which was similar for all the experimental and control groups. This normal instruction lasted about 45 minutes. The last half of the class was for both story retelling task, in which all the groups were similar, and for treatment part, in which the control and experimental groups were different.

In every session of the study, six sessions, which was tape recorded for the later analysis, all participants were assigned one story from Steps to Understanding (Hill, 1988) in a way that the stories within groups were different, due to the avoidance of the practice effect, and the stories between groups were the same. After the assignment of the story for every participant of the study, they were given 4 minutes and were asked to read and summarize it. The reason for this kind of time limit was to make them not to memorize the story. When they finished reading and summarizing their own special story, they were asked to retell it to the class. During the retelling of the story which was audio recorded for later analysis, the three groups were different with respect to the presence or absence of feedback and the kind of feedback they received; in other words, whereas the control group's members received no feedback on their errors, the experimental group's members received form focused feedback to all errors with the simple past tense.

In addition to this difference between the experimental groups and the control group, the two experimental groups differed in terms of manner and type of feedback they received; while the first experimental group's members received online recast on their targeted errors, the second experimental group's members received feedback when they finished the story retelling; indeed in the second experimental group, the researcher waited to the end of every member's story retelling and gave delayed feedback on his simple past errors by presenting the errors on the board, correcting explicitly, and providing some metalinguistic explanations to the whole class. This process continued in every session of the study in the same manner. When the treatment sessions finished, it was the time for the transcription and coding of the oral data. To this end, the recorded data for all groups and their members in every session of the treatment were transcribed and analyzed by the researcher. Since the focus of the study was on the effects of feedback on oral accuracy, the data were transcribed and coded with respect to the accurate use of simple past tense. 
To code accuracy, following the previous studies of Mehnert (1998), Yaghubi-Notash (2007), and Rahimpour (2008), it was operationlized as the number of Error-free T-units per T-units i.e., the percentage of T-units that do not contain any errors. T. unit is defined as "one main clause plus whatever subordinate clauses, phrases, and words happen to be attached or embedded within it" (Mehnert, 1998, p. 91). The inter rater reliability for coding was obtained by having another instructor identify and code the data. The reliability was 0.89 . The mean percentage of accurate use of simple past tense for every individual and every group in every session of the study was calculated and analyzed. Then the groups' scores during the six sessions of the study were submitted to another one way ANOVA for further analysis. In order to find out which one of the experimental groups and in which sessions of the study, differed significantly from the control group, a Dunnett $t$ test was used. A Tukey HSD test was also used to find out the existence or nonexistence of the significant differences between the two experimental groups during the six sessions of the study.

\section{Results}

\subsection{Planned focus on form and oral accuracy}

To address the hypotheses put forth at the outset of the study, the scores obtained on the six sessions of the study were submitted to a one way ANOVA. The results of the ANOVA are displayed in Table 1.

\section{$<$ Table 1 about here>}

According to Table 1, while the significance of ANOVA for these groups in the first five sessions of the study were bigger than the $\alpha=0.05$ and therefore the equality assumption is accepted in the first five sessions of the study, in the session6 it was $0.31 ; \mathrm{F}(2,49)=3.736$, $\mathrm{p}$-value $=.031$ which was smaller than $\alpha=0.05$ and therefore the inequality of groups is accepted at the 0.95 level of significance in the session 6 . In other words, the planned focus on form showed its effects in the session6 which was the last session of the study.

Having realized that there were significant differences among groups in the last session, there was a need to find out which groups were significantly different from each other, therefore, the oral data were submitted to a Dunnet $t$ test to compare the all groups against the control group. Table 2 presents the results of this test for the six sessions of treatments.

\section{$<$ Table 2 about here>}

As it is clear in Table 2, the Dunnet t test revealed that during the first five sessions of the study there were no significant differences between the two experimental groups and the control group and it was only session 6 in which the significant differences between two experimental groups and the control group appeared. In other words, in the session 6 the second group which received recast on the erroneous production outperformed the control group which received no feedback ( $\mathrm{p}$-value $=.040<\alpha=0.05$ ). In addition to this difference between the second group and the control group, the third group which received delayed explicit and metalinguistic feedback on its erroneous production outperformed the control group, ( $p$-value $=.044<\alpha=0.05$ ). These findings lead to the acceptance of the first hypothesis which was the existence of the significant differences between the experimental groups on one hand and the control group on the other hand. Regarding the oral accuracy, planned focus on form, corrective feedback, targeted on the simple past tense was more effective in enabling learners to speak accurately than lack of focus on from or corrective feedback.

\subsection{The effects of different feedback types on oral accuracy}

In order to test our second hypothesis, Tukey HSD test was used to find out whether there was a significant difference between the two experimental groups regarding the oral accuracy of their production. Table 3 presents the results of this test for the session 6.

$<$ Table 3 about here>

Since p-value $=.994>\alpha=0.05$, the second hypothesis of the study, the existence of the significant differences between the two experimental groups, was rejected and the second null hypothesis which was the lack of the significant differences between the two groups was accepted. In other words, the results show that the two experimental groups were not significantly different regarding the oral accuracy of their production.

\section{Discussion and Conclusion}

Based on the findings summarized in the previous section, the research questions of the study are answered and discussed as follows:

The first research question of the current study was: Do learners who have received planned focus on form, corrective feedback, on their simple past tense errors in their story retellings show greater improvement on their oral accuracy than those who have not? The findings indicated that both experimental groups which received corrective feedback, although 
a different type of feedback, performed significantly better than the control group in the session 6 which was the last session of oral production and treatment. In other words, there were significant differences between the oral accuracy of the two experimental groups on the one hand, and the control group on the other hand, in the last session. Indeed, there was a significant difference between the oral accuracy of the first experimental group which received recast on the simple past tense errors and that of the control group which received no feedback in the last session. In addition to the difference between the first experimental group and the control group, there was a significant difference between the oral accuracy of the second experimental group, which received delayed explicit feedback, and that of the control group in the last session. Recasts and delayed explicit and metalinguistic treatment thus both appear to have been effective in the improvement of the EFL learners' oral accuracy. Therefore, the answer to Research Question 1 was yes, planned focus on form, corrective feedback focused on simple past tense errors, improved Iranian EFL learners' oral accuracy.

The second research question was: Do learners who have received delayed explicit and metalinguiatic feedback on their simple past tense errors show greater improvement on their oral accuracy than those who have received recasts? The findings indicated that in spite of the differences between the two experimental groups' means during the six sessions of oral production and treatment, these means' differences were not statistically significant. Therefore, the answer to the second research question was no, there were no significant differences between the two feedback types' effects on the development of the learners' oral accuracy. Indeed, the two feedback types were equally effective in the development of the oral accuracy. Considering these findings, it can be suggested that the intensive recasts focused on a specific forms are not different from explicit types of feedback.

Considering the research questions 1 , the findings from the present study provide support to the claim that embedding CF within communicative activities is more effective than participation in such activities without CF. The results are consistent with previous claims for the efficacy of focus on from (Doughty \& Williams, 1998; Lightbown \& Spada, 1990; Long, 1996; Long \&Robinson, 1998; Skehan, 1996; Spada \& Lightbown, 1993). These results also support Lightbown and Spada's (1990) claim that "accuracy, fluency, and overall communicative skills are probably best developed through instruction that is primarily meaning focused but in which guidance is provided through timely form focused activities and correction in context" (p. 443). They also provide support for previous feedback studies (e.g., Doughty \& Varela, 1998) which revealed that negative feedback is beneficial to L2 learning when it specifically targets particular forms. They are in agreement with Schmidt's (1990, 2001) noticing hypothesis which holds that noticing, a cognitive process that involves attending to the input learners receive, is inevitably a conscious process and is a necessary condition for second language learning. They are also in sharp contrast with the proponents of non-interface hypothesis such as Krashen (1982) who referred to "error correction as a serious mistake and argued that it should be limited to rules that can be learnt" (p. 74).

Regarding the appearance of the effects of planned focus on form in session 6, these results are in line with Ellis, Loewen, \& Erlam (2006), who reported that corrective feedback in the form of metalinguistic comments did not result in statistically significant gains in the accuracy with English past tense-ed by adult L2 learners in an immediate post test but did in a delayed test administered two weeks later. Thus, it is also necessary to explain why this might occur. The likely explanation according to Ellis (2007) lies in the nature of the target structure. According to Ellis (2007), for example, whereas explicit corrective feedback had an immediate effect on the acquisition of comparative adjective, it only had a delayed effect on the acquisition of past tense-ed. This can be generalized to the current study in which the learners had solid explicit knowledge of the simple past tense at the beginning of the study and the instruction activated the learners' existing explicit knowledge, which primed them to gain more control to this feature with the result that gains became apparent in the delayed post test and session 6 which was the last session of the study.

Considering the research questions 2, the findings are in line with Kim and Mathes (2001), in a study that replicated that of Carroll and Swain (1993), who failed to find any statistically significance differences in the scores of the explicit and implicit groups. The findings are also in line with Hyung-Sook's study (2009) who examined the relative effects of explicit and implicit feedback in the learning of Korean as a less commonly taught foreign language and reported that both the experimental groups outperformed the control group that received no feedback and also it showed that there was no significant difference between the two experimental groups. The absence of a statistically significant difference between the recast and explicit feedback suggests that recasts were as effective as explicit types of feedback. One reason for this equality can be that they provided both positive and negative evidence in a way that the learners recognized their corrective functions and the gaps between their own utterances and the corrected forms. In this respect the finding is consistent with Carroll (2001) who claims that CF cannot facilitate learning unless learners recognize its corrective function. Another reason for this equality in the effects of recasts and delayed explicit feedback could be due to the explicit nature of recasts in the current study; since recasts were intensively directed at a single structure, simple past tense, and their illocutionary force as corrections was quite transparent, with rising intonation or emphasis, they should 
be seen as an explicit form of feedback according to Ellis (2008). This suggests that the intensive nature of recasts directed at a single structure can be as effective as that of explicit feedback in leading learners to detect the intent and content of corrective feedback.

\section{Limitations of the Study and Pedagogical Implications}

As in all classroom studies, there are inevitable limitations. First, the researcher was forced to use intact classes. Second, the length of treatments was very short. Third, the structure was chosen for study was a structure that learners had already begun to acquire. In one respect, this can be considered strength. As it enabled us to examine whether corrective feedback and what type of corrective feedback works best for structures already partially acquired. However, in another respect, it constitutes a weakness, in that we are unable to say whether corrective feedback (and what type of feedback) is effective in establishing new knowledge. Fourth, the present research included only two types of correction: Recast and delayed explicit. Fifth, the focus was on a single structure, simple past tense. Sixth, the all participants of the study were male. Another limitation was related to the focus of the study which was on the effects of feedback on oral accuracy and explicit knowledge in a way that the study of its effects on fluency and complexity were completely ignored.

The study provides strong support for the assumption that a timely combination of formal instruction and communication oriented instruction is highly beneficial to L2 learners especially in an EFL situation in which the instruction is based on a communicative language teaching. That the control group, which received no feedback, did not significantly improve their scores on the post tests is also significant in showing that purely meaning focused activities without any kind of form focused treatment do not lead the learners to improve their oral accuracy .The results of this study also suggest that the integration of planned focus on form into meaning based activities can positively affect L2 learning when it has a particular linguistic focus. There are three other major pedagogical implications arising from this study: (1) having even a limited number of students participated in focus on from tasks can be beneficial to the entire class; (2) having even a limited number of treatment sessions can be beneficial to the L2 learners; (3) both of the focus on from treatments, recasts and explicit feedback, can help learners improve not only their oral accuracy but also their explicit knowledge of the target structure.

\section{References}

Carroll, S. (2001). Input and evidence: The raw material of second language acquisition. Amsterdam: Benjamines.

Carroll, S., \& Swain, M. (1993). Explicit and implicit negative feedback: An empirical study of the learning of linguistic generalizations. Studies in Second Language Acquisition, 15, 357-366. http://dx.doi.org/10.1017/S0272263100012158

Dekeyser, R. (1998). Beyond focus on form: Cognitive perspectives on learning and practicing second language grammar. In C. Doughty, \& J. Williams (Eds.), Focus on form in classroom second language acquisition (pp.42-63). Cambridge; Cambridge University Press.

Doughty, C. J. (2001). Cognitive underpinnings of focus on form. In P. Robinson (Ed.), Cognition and second language instruction (pp. 206-257). New York: Cambridge University Press.

Dougthy, C, J., \& Varela, E. (1998). Communicative focus on form. In C. J. Doughty, \& J. Williams (Eds.), Focus on form in classroom second language acquisition (pp. 114-138). New York: Cambridge University Press.

Dougty, C. J., \& Williams, J. (1998). Pedagogical choices in focus on from. In C. J. Doughty, \& J. Williams (Eds.), Focus on form in classroom second language acquisition (pp. 197-261). New York: Cambridge University Press.

Dulay, H., \& Burt, M. (1973). Should we teach children syntax? Language Learning, 23, 245-58. http://dx.doi.org/10.1111/j.1467-1770.1973.tb00659.x

Ellis, R. (2001). Investigating form-focused instruction. Language Learning, 51(1), 1-46.

Ellis, R. (2003). Task based language learning and teaching. Oxford, UK: Oxford University Press.

Ellis, R. (2005). Principles of instructed language learning. Asian EFL Journal, 7(3).

Ellis, R. (2007). The different effects of corrective feedback on two grammatical structures. In A. Mackey (Ed.), Conversational Interaction in Second Language Acquisition (339-360). Oxford: Oxford University Press.

Ellis, R. (2008). The study of second language acquisition. Oxford: Oxford University Press.

Ellis, R., Basturkmen, H., \& Leowen, S. (2001a). Learner uptake in communicative ESL lessons. Language Learning, 51(2), 281-318. http://dx.doi.org/10.1111/1467-9922.00156 
Ellis, R., Basturkmen, H., \& Leowen, S. (2001b). Preemptive focus on form in the ESL classroom. TESOL Quarterly, 35(3), 407-432. http://dx.doi.org/10.2307/3588029

Ellis. R., Loewen, S., \& Erlam, R. (2006). Implicit and explicit corrective feedback and the acquisition of L2 grammar. Studies in Second Language Acquisition, 28, 339-358. http://dx.doi.org/10.1017/S0272263106060141

Ellis, R., \& Sheen, Y. (2006). Reexamining the role of recasts in second language acquisition. Studies in Second Language Acquisition, 28, 575-600. http://dx.doi.org/10.1017/S027226310606027X

Gass, S. (1990). Second and foreign language learning: same, different or none of the above? In B. Vanpatten, \& J. Lee (Eds.), Second Language Acquisition- Foreign Language Learning (pp. 34-44). Clevedon: Multilingual Matters.

Gass, S. (1997). Input, Interaction, and the second Language Learner. Mahwa, N. J.: Lawrence Erlbaum.

Hill, L. A. (1988). Steps to Understanding. Oxford: Oxford University Press.

Howatt, A. (1984). A history of English language teaching. Oxford, UK: Oxford University Press.

Hymes, D. (1971). On communicative competence. Philadelphia: University of Pennsylvania Press.

Hyung-Sook Kang (2009). The relative efficiency of explicit and implicit feedback in the learning of a less-commonly-taught foreign language. IRAL, 47, 303-324. http://dx.doi.org/10.1515/iral.2009.013

Kim, H., \& Mathes, G. (2001). Explicit vs. implicit corrective feedback. Korea TESOL Journal, 4, 1-15.

Krashen, S. (1982). Principals and Practice in Second Language Acquisition. Oxford: Pergamon.

Leeman, J. (2003). Recasts and second language development: Beyond negative evidence. Studies in Second Language Acquisition, 25, 37-63.

Lightbown, P. M., \& Spada, N. (1990). Focus on form and corrective feedback in communicative language teaching: Effects on second language learning. Studies in Second Language Acquisition, 12, 429-448. http://dx.doi.org/10.1017/S0272263100009517

Long, M. H. (1983). Native speaker/nonnative speaker conversation and negotiation of comprehensible input. Applied Linguistics, 4, 126-41. http://dx.doi.org/10.1093/applin/4.2.126

Long. M. H. (1991). Focus on form: A design feature in language teaching methodology. In K. De Bot, R. Ginsberg, \& C. K. Krasch (Eds.), Foreign language research in cross-cultural perspective (pp. 39- 52). Amsterdam: Benjamins.

Long. M. H. (1996). The role of the linguistic environment in second language acquisition. In W. C. Ritchie, \& T. K. Bhatia (Eds.), Handbook of language acquisition (pp. 413-468). San Diego: Academic Press. http://dx.doi.org/10.1016/B978-012589042-7/50015-3

Long, M. H. (2000). Task based language teaching. Oxford: Blackwell.

Long, M. H., \& Robinson, P. (1998). Focus on form: Theory, research and practice. In C. J. Dougthy, \& J. Williams (Eds.). Focus on form in classroom second language acquisition (pp. 15-41). New York: Cambridge University Press.

Lyster, R. (2004). Differential effects of prompts and recasts, and explicit correction in form focused instruction. Studies in Second Language Acquisition, 26, 399-432. http://dx.doi.org/10.1017/S0272263104263021

Mehnert, U. (1998). The effects of different lengths of time for planning on second language performance. Studies in Second Language Acquisition, 20, 83-108. http://dx.doi.org/10.1017/S0272263198001041

Prabhu, N. S. (1987). Second language pedagogy. Oxford, UK: Oxford University Press.

Rahimpour, M. (2008). Implementation of task- based approaches to language teaching. Research on Foreign Languages Journal of Faculty of Letters and Humanities, 41, 45-61.

Schmidt, R. (1990). The role of consciousness in second language learning. Applied linguistics, 11, $129-158$. http://dx.doi.org/10.1093/applin/11.2.129

Schmidt, R. (2001). Attention. In P. Robinson (Ed.), Cognition and second language instruction (pp. 3-32). New York: Cambridge University Press.

Sharwood Smith, M. (1981). Consciousness raising and second language learner. Applied Linguistics, 2, $159-168$. http://dx.doi.org/10.1093/applin/2.2.159

Sharwood Smith, M. (1993). Input enhancement in instructed SLA: Theoretical bases. Studies in Second Language Acquisition, 15 (2), 156-179. 
Skehan, P. (1996). A framework for the implication of task based instruction. Applied Linguistics, 17, 38-61.

Spada, N., \& Lightbown, P. (1993). Instruction and the development of questions in L2 classrooms. Studies in Second Language Acquisition, 15, 205-224. http://dx.doi.org/10.1017/S0272263100011967

Swain, M. (1985). Communicative competence: Some roles of comprehensible input and comprehensible output in its development. In S. M. Gass, \& C. Madden (Eds.), Input in second language acquisition (pp. 235-253). Rowley, MA: Newbury House.

Swain, M. (1991). French immersion and its offshoots: Getting two for one. In B. Freed (Ed.), Foreign Language acquisition: Research and the classroom (pp. 91-103). Lexington, MA: Heath.

Swain, M. (1995). Three functions of output in second language learning. In G. Cook, \& B. Seildlhofer (Eds.), Principles and practice in applied linguistics: Studies in honor of H. G. Widdowson (pp.125-144). Oxford: Oxford University Press.

Swain, M. (1998). Focus on from through conscious reflection. In C. Doughty, \& J. Williams (Eds.). Focus on from in classroom second language acquisition (pp.64-81). Cambridge: Cambridge University Press.

Swain, M., \& Lapkin, S. (1998). Problems in output and the cognitive processes they generate: A step towards second language learning. Applied Linguistics, 16, 370-391.

Terrell, T. (1977). A natural approach to second language acquisition and learning. The Modern Language Journal, 61, 325-36.

Trahey, M., \& White, L. (1993). Positive evidence in second language classroom. Studies in Second Language Acquisition, 15, 181-204. http://dx.doi.org/10.1017/S0272263100011955

Wilkins, D., (1976). Notional syllabuses. Oxford: Oxford University Press.

Yaghubi-Notash, M. (2007). Variability in L2: Exploring gender influence in task-prompted oral performance (Unpublished doctoral dissertation). University of Tabriz, Tabriz, Iran

Table 1. Summary of the Results of the ANOVA

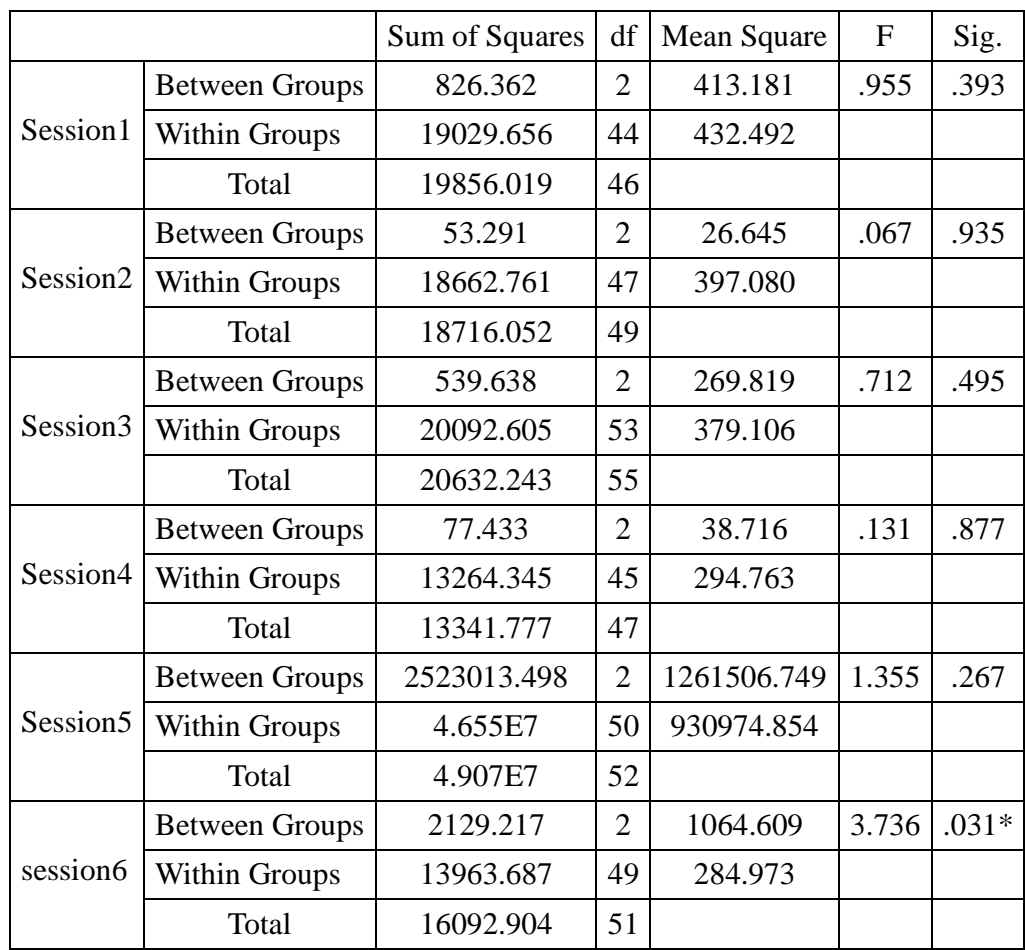


Table 2. Summary of the Results of Dunnet t-test for Oral Data

\begin{tabular}{|c|c|c|c|c|c|c|c|c|c|c|}
\hline \multirow{2}{*}{\multicolumn{2}{|c|}{ Dependent Variable }} & \multirow{2}{*}{\multicolumn{2}{|c|}{ (I) Group }} & \multirow{2}{*}{\multicolumn{2}{|c|}{ (J) Group }} & \multirow{3}{*}{\begin{tabular}{|c} 
Mean \\
$\begin{array}{c}\text { Difference } \\
(\mathrm{I}-\mathrm{J})\end{array}$ \\
5.30333
\end{tabular}} & \multirow{3}{*}{$\begin{array}{l}\text { Std. Error } \\
7.59379\end{array}$} & \multirow{3}{*}{$\begin{array}{l}\text { Sig. } \\
.707 \\
\end{array}$} & \multicolumn{2}{|c|}{$\begin{array}{l}95 \% \text { Confidence } \\
\text { Interval }\end{array}$} \\
\hline & & & & & & & & & Lower & Unper \\
\hline \multirow{12}{*}{ Dimension1 } & \multirow[t]{2}{*}{ Session 1} & \multirow{2}{*}{ dimension2 } & 2.00 & dimension3 & 1.00 & & & & -12.0345 & 22.6412 \\
\hline & & & 3.00 & dimension3 & 1.00 & 10.18263 & 7.36706 & .291 & -6.6376 & 27.0028 \\
\hline & \multirow[t]{2}{*}{ Session2 } & \multirow{2}{*}{ dimension2 } & 2.00 & dimension 3 & 1.00 & 1.80489 & 6.94083 & .952 & -14.0294 & 17.6392 \\
\hline & & & 3.00 & dimension 3 & 1.00 & -.66000 & 6.83486 & .993 & -16.2525 & 14.9325 \\
\hline & \multirow[t]{2}{*}{ Session3 } & \multirow{2}{*}{ dimension2 } & 2.00 & dimension3 & 1.00 & 2.83559 & 6.58497 & .874 & -12.1189 & 17.7901 \\
\hline & & & 3.00 & dimension3 & 1.00 & -4.60262 & 6.25413 & .682 & -18.8058 & 9.6006 \\
\hline & \multirow[t]{2}{*}{ Session4 } & \multirow{2}{*}{ dimension2 } & 2.00 & dimension 3 & 1.00 & 1.34848 & 6.28309 & .967 & -13.0013 & 15.6982 \\
\hline & & & 3.00 & dimension 3 & 1.00 & 3.01174 & 5.89902 & .830 & -10.4608 & 16.4843 \\
\hline & \multirow[t]{2}{*}{ Session5 } & \multirow{2}{*}{ dimension 2} & 2.00 & dimension 3 & 1.00 & 488.20767 & 337.32153 & .262 & -280.0470 & 1256.4624 \\
\hline & & & 3.00 & dimension3 & 1.00 & 7.42267 & 313.47977 & 1.000 & -706.5321 & 721.3774 \\
\hline & \multirow[t]{2}{*}{ Session6 } & \multirow{2}{*}{ dimension 2} & 2.00 & dimension 3 & 1.00 & $13.75799^{*}$ & 5.80023 & $.040^{*}$ & .5372 & 26.9787 \\
\hline & & & 3.00 & dimension 3 & 1.00 & $13.15889^{*}$ & 5.62705 & $.044^{*}$ & .3329 & 25.9849 \\
\hline
\end{tabular}

Table 3. Results of Tukey HSD Test for the Experimental Groups' Oral Data

\begin{tabular}{|c|c|c|c|c|c|c|c|c|}
\hline \multirow{2}{*}{\multicolumn{2}{|c|}{ Dependent Variable }} & \multirow{2}{*}{ (I) Group } & \multirow{2}{*}{ (J) Group } & \multirow{2}{*}{ Mean Difference (I-J) } & \multirow{2}{*}{ Std. Error } & \multirow{2}{*}{ Sig. } & \multicolumn{2}{|c|}{$95 \%$ Confidence Interval } \\
\hline & & & & & & & Lower Bound & Upper Bound \\
\hline \multirow{6}{*}{ Session6 } & \multirow{6}{*}{ Tukey HSD } & \multirow{2}{*}{1.00} & 2.00 & -13.75799 & 5.80023 & $.055^{*}$ & -27.7767 & .2607 \\
\hline & & & 3.00 & -13.15889 & 5.62705 & .060 & -26.7590 & .4413 \\
\hline & & \multirow{2}{*}{2.00} & 1.00 & 13.75799 & 5.80023 & $.055^{*}$ & -.2607 & 27.7767 \\
\hline & & & 3.00 & .59910 & 5.80023 & .994 & -13.4196 & 14.6178 \\
\hline & & \multirow{2}{*}{3.00} & 1.00 & 13.15889 & 5.62705 & $.060^{*}$ & -.4413 & 26.7590 \\
\hline & & & 2.00 & -.59910 & 5.80023 & .994 & -14.6178 & 13.4196 \\
\hline
\end{tabular}

